\title{
Synthesis and Characterization of Chitosan Particles Loaded with Antioxidants Extracted from Chia (Salvia hispanica L.) Seeds
}

\author{
Gema Morales-Olán $\mathbb{D}^{1},{ }^{1}$ Silvia Luna-Suárez $\mathbb{D}^{1},{ }^{1}$ Juan De Dios Figueroa-Cárdenas $\mathbb{D}{ }^{2}$ \\ Monica Corea $\mathbb{D}^{3}{ }^{3}$ and Marlon Rojas-López $\mathbb{D}^{1}$ \\ ${ }^{1}$ Instituto Politécnico Nacional, Centro de Investigación en Biotecnología Aplicada, Ex Hacienda De San Juan Molino, \\ Carretera Estatal Santa Ines, Tecuexcomac-Tepetitla. Km. 1.5, Tepetitla, Tlaxcala 90700, Mexico \\ ${ }^{2}$ CINVESTAV Unidad Querétaro, Libramiento Norponiente No. 2000, Fracc Real de Juriquilla, Querétaro, Qro 76230, Mexico \\ ${ }^{3}$ Instituto Politécnico Nacional, Escuela Superior de Ingenieria Química e Industrias Extractivas, UPALM, Zacatenco, \\ Ciudad de México 07732, Mexico
}

Correspondence should be addressed to Marlon Rojas-López; marlonrl@yahoo.com.mx

Received 26 February 2021; Accepted 31 May 2021; Published 15 June 2021

Academic Editor: Chanbasha Basheer

Copyright (C) 2021 Gema Morales-Olán et al. This is an open access article distributed under the Creative Commons Attribution License, which permits unrestricted use, distribution, and reproduction in any medium, provided the original work is properly cited.

\begin{abstract}
Chia (Salvia hispanica L.) seeds contain antioxidants with great benefits for health and are widely used in the food industry. Antioxidants can be degraded by environmental factors, decreasing their biological activity. Their encapsulation in chitosan $(\mathrm{CH})$ particles represents an alternative to protect them and increases their application. The encapsulation efficiency (\%EE) of the antioxidants in the $\mathrm{CH}$ particles depends on the synthesis conditions. In this study, two methods for encapsulation of chia extract in chitosan particles were evaluated: method $\mathrm{A}, 0.05 \% \mathrm{CH}$ in $1 \%$ acetic acid was mixed with $0.07 \%$ of tripolyphosphate (TPP) and method $\mathrm{B}, 0.3 \% \mathrm{CH}$ in $2 \%$ acetic acid was mixed with $1 \% \mathrm{TPP}$. The results showed that the $\% \mathrm{EE}$ decreased with the concentration of the extract, and the FTIR analysis suggested that the compounds of the extract were adsorbed on the surface of the particles. Dynamic light scattering and zeta potential analysis showed that the particles of method A are unstable and with a tendency to agglomerate, and the particles of method $\mathrm{B}$ are stable. The highest \%EE was obtained with $0.2 \mathrm{mg} \cdot \mathrm{mL}^{-1}$ (method A) and $1.0 \mathrm{mg} \cdot \mathrm{mL}^{-1}$ (method B) of the extract. The higher loading capacity (\%LC) (16-72\%) was exhibited by the particles of method A. The best particle yield (62-69\%) was observed for method B. The particles with the extract adsorbed showed antioxidant activity $(5-60 \%)$ at $25^{\circ} \mathrm{C}$; however, in the particles with the extract encapsulated, the activity increased after subjecting to acidic conditions at $40^{\circ} \mathrm{C}$ due to the breakdown of the particles. The results obtained will allow choosing the appropriate conditions for the synthesis of chitosan particles loaded with chia extracts with specific characteristics (\%EE, \%LC, size, and type) according to their future applications. The particles could be used in food and pharmaceutical industries and even in edible films for food packaging.
\end{abstract}

\section{Introduction}

Chia (Salvia hispanica L.) seeds present great benefits for nutrition and human health. These seeds provide proteins, carbohydrates, fatty acids, and fiber [1], and they are an important source of phenolic compounds, such as kaempferol $\left(0.403 \mathrm{mg} \cdot \mathrm{g}^{-1}\right.$ of seed), quercetin $\left(0.248 \mathrm{mg} \cdot \mathrm{g}^{-1}\right.$ of seed), chlorogenic acid $\left(0.102 \mathrm{mg} \cdot \mathrm{g}^{-1}\right.$ of seed), myricetin $\left(0.010 \mathrm{mg} \cdot \mathrm{g}^{-1}\right.$ of seed), and gallic acid $\left(0.0116 \mathrm{mg} \cdot \mathrm{g}^{-1}\right.$ of seed $)$ [2-4]. It has been described that phenolic compounds protect humans against several chronic degenerative diseases [5] and antioxidants are also used as additives for food preservation. However, an important disadvantage is their instability during the processing, distribution, storage, and consumption of food [6]. They can be degraded by various factors (temperature, light, $\mathrm{pH}$, enzymes, and other nutrients) [7], limiting their activity and potential health benefits. To avoid these phenomena, encapsulation is used, which allows trapping active substances within a material, improving its bioavailability, and facilitating the application of the plant extracts [8]. 
Protected by the particles, the phenolic compounds can be used in manufactured nutraceutical functional foods in the pharmaceutical and cosmetic industry. Among the polymeric materials applied for encapsulation, the $\mathrm{CH}$ composed of $\beta$-(1-4)-linked D-glucosamine (deacetylated unit) and $\mathrm{N}$-acetyl-D-glucosamine (acetylated unit) presents ideal characteristics and is biocompatible, biodegradable, nontoxic, and inexpensive [9]. The synthesis of chitosan particles can occur through many routes, but the ionic gelation reaction is one of the most widely used. The encapsulation of extracts and essential oils from plants in chitosan nanoparticles has been reported $[9,10]$. In the literature, there are numerous reports on the encapsulation of chia seed oil using techniques such as layer-by-layer electrostatic deposition of chitosan [11] and atomization and lyophilization using soy protein gum arabic and maltodextrin $[12,13]$. In addition, the use of chia seed mucilage as a wall material to encapsulate the oils extracted from the same seed has been evaluated [14, 15]. However, there is no information about the loading of hydroalcoholic antioxidant chia extract into chitosan nanoparticles. Encapsulation of a specific compound of the extract is desirable, but separative methods make the process more expensive and, in some cases, low extraction yield is obtained. Furthermore, it has been reported that the combination of different compounds in an extract can generate a synergy, that is, an increase in the biological activity because they act together [16]. The \%EE of the extracts of chitosan particles synthesized by ionic gelation depends on the molecular weight of the polymer, the degree of deacetylation, the concentration of precursors, the $\mathrm{pH}$ of the solution, the relationship between the precursors, as well as the affinity between the extract and the $\mathrm{CH}[17,18]$. Therefore, it is necessary to evaluate different conditions to find efficient encapsulation methodologies. The aim of this work was to evaluate two methods of encapsulation of the extract of chia seeds in chitosan particles synthesized under the ionic gelation methodology. The $\% \mathrm{EE}, \%$ LC, and the particle yield (\%PY) of the particles were determined using different concentrations of the extract $\left(0.2-15 \mathrm{mg} \cdot \mathrm{mL}^{-1}\right)$. The particles were also characterized by FTIR, dynamic light scattering, zeta potential, and morphologically by SEM. In addition, the effect of temperature $\left(25^{\circ} \mathrm{C}\right.$ and $\left.40^{\circ} \mathrm{C}\right)$ and $\mathrm{pH}(6$ and 10$)$ on particles and the antioxidant capacity was evaluated.

\section{Materials and Methods}

2.1. Materials. Medium-molecular-weight CH (190$310 \mathrm{kDa}$ ) with a degree of deacetylation of $75-85 \%$, TPP, glacial acetic acid, 2,2-diphenyl-1-picrylhydrazyl (DPPH), and ethanol were obtained from Sigma Aldrich (Sigma Co., San Luis, E.U.). Chia seeds were purchased from a local market in Puebla City, Mexico. They were cleaned manually and were passed through a 20-mesh screen. The flour was generated by grinding the seeds in a food processor and passing them through a $35-$ mesh screen. The flour was stored at $4^{\circ} \mathrm{C}$ until its use.

2.2. Obtaining of Chia Seeds Extract. To obtain the chia extract, $0.5 \mathrm{~g}$ of chia flour was mixed with $3 \mathrm{~mL}$ of the $80 \%$ aqueous ethanol solution for $24 \mathrm{~h}$ at $25^{\circ} \mathrm{C}$ and centrifuged at $6,000 \mathrm{rpm}$ for $10 \mathrm{~min}$. The alcohol of the extract was removed by using Rotavapor and the water by lyophilization. The extract was stored at $4^{\circ} \mathrm{C}$.

\subsection{Synthesis of Chitosan Particles and Chia Extract-Loaded} Particles. The particles were prepared by ionic gelation of $\mathrm{CH}$ with TPP. The methods described by Antoniou et al. [19] (method A) and Nadirah et al. [20] (method B) with some modifications were used to evaluate the encapsulation of chia extract in chitosan particles. In method A, 0.05\% (w/v) $\mathrm{CH}$ was dissolved in $1 \%(\mathrm{v} / \mathrm{v})$ aqueous glacial acetic acid with $\mathrm{pH} 4.8 .10 .0 \mathrm{~mL}$ of the aqueous solution of TPP $(0.07 \% \mathrm{w} / \mathrm{v})$ was added dropwise to $42.0 \mathrm{~mL}$ of the $\mathrm{CH}$ solution under vigorous magnetic stirring $(1000 \mathrm{rpm})$ at room temperature. For the synthesis of the particles that incorporate the chia extract, different concentrations of the extract $(0.2,0.3,0.4$, $0.5,1.0,2.0,3.0,4.0,5.0$, and $10.0 \mathrm{mg} \cdot \mathrm{mL}^{-1}$ ) were prepared in the TPP solution with agitation until the dissolution is completed. The solution extract-TPP was added dropwise to the $\mathrm{CH}$ solution under vigorous magnetic stirring at room temperature for $10 \mathrm{~min}$. In method $\mathrm{B}, 0.3 \%(\mathrm{w} / \mathrm{v}) \mathrm{CH}$ was dissolved in $2 \%(\mathrm{v} / \mathrm{v})$ of acetic acid. The nanoparticles were obtained upon the addition of $4.8 \mathrm{~mL}$ of $1 \% \mathrm{TPP}(\mathrm{w} / \mathrm{v})$ into $47.2 \mathrm{~mL}$ of the $\mathrm{CH}$ solution $(\mathrm{pH} 2.8)$ under vigorous magnetic stirring at room temperature for $1 \mathrm{~h}$. Several concentrations of the extract $(1.0,2.0,3.0,4.0,5.0,10.0$, and $15.0 \mathrm{mg} \cdot \mathrm{mL}^{-1}$ ) in the TPP solution were added to the $\mathrm{CH}$ solution to obtain the loaded particles. In both methodologies, the particles were recovered by centrifugation at $13,000 \mathrm{rpm}$ for $30 \mathrm{~min}$ at $25^{\circ} \mathrm{C}$. Three washes with deionized water were performed to remove the remnants of the synthesis. The particles were lyophilized and kept at $4^{\circ} \mathrm{C}$ until further analysis. The particles without extract were named as blank particles.

\subsection{Encapsulation Efficiency (\%EE), Nonencapsulated Extract} (\%NE), Loading Capacity (\%LC), and Particle Yield (\%PY) of the Particles. The \%EE was determined by analyzing the supernatant of the chitosan particles by UV-Visible spectrophotometry at a wavelength of $320 \mathrm{~nm}$. This is the wavelength of maximum absorption of the chia extract that was obtained by a UV-Visible scan $(200-900 \mathrm{~nm})$. In this wavelength, the precursors $\mathrm{CH}$ and TPP did not show absorbance. A calibration curve was generated with the extract $\left(0-1.5 \mathrm{mg} \cdot \mathrm{mL}^{-1}, y=1.408 x+0.0055, R^{2}=0.99\right)$ to calculate the concentration of the extract in the supernatant. The $\% \mathrm{EE}$, \%LC, and \%PY of the particles were calculated using 
equations (1)-(3), respectively. The \%NE was obtained by difference with \%EE.

$$
\begin{aligned}
& \% E E=\left(\frac{\text { weight of loaded chia extract }}{\text { weight of initial chia extract }}\right) \times 100, \\
& \% L C=\left(\frac{\text { weight of loaded chia extract }}{\text { weight of sample }}\right) \times 100, \\
& \% P Y=\left(\frac{\text { nanoparticles weight }}{\text { total solids weight }(\mathrm{CH}+\mathrm{TPP}+\text { chia extract })}\right) \times 100 .
\end{aligned}
$$

2.5. Structural Characterization of the Particles by FTIR. The lyophilized particles were characterized using an FTIR spectrometer (Bruker Vertex 70, Germany) equipped with an attenuated total reflectance (ATR) accessory. The spectral measurements were recorded in the wavenumber range between 4000 and $500 \mathrm{~cm}^{-1}$.

2.6. Particle Morphology and Size. The particles were examined using the scanning electron microscope SEM-FEJOL 7610F (Tokyo, Japan) with an Oxford EBSD detector operating at a $2.0 \mathrm{kV}$ voltage acceleration and a secondary electron detector (SEI). The samples were mounted dry on a carbon tape and coated with Au/Pd. SEM images were analyzed with ImageJ $1.52 \mathrm{a}$ program (National Institute of Health, USA) to determine the size of the particles.
2.7. Dynamic Light Scattering and Zeta Potential. The distribution particle diameter and zeta potential $(\zeta)$ of the synthesized particles were measured using a Zetasizer Nano ZSP (Malvern Instruments, United Kingdom). The samples were centrifuged and redispersed in distilled water. The measurements were made in triplicate at $25^{\circ} \mathrm{C}$.

2.8. DPPH Radical Scavenging Activity of the Particles. The antioxidant capacity was determined by the DPPH radical with the methodology proposed by Parejo et al. [21] with some modifications. The particles were mixed with a $100 \mathrm{mM}$ DPPH methanol solution, placed under stirring for $30 \mathrm{~min}$ in the dark. Then, they were centrifuged at 6,000 rpm for $1 \mathrm{~min}$ and the supernatant was measured at $517 \mathrm{~nm}$. The percentage of the DPPH scavenging activity was determined using equation (4). The results show the mean of three replicates \pm SD.

$$
\text { DPPH scavenging activity }(\%)=\left[\frac{\text { absorbance }_{\text {control }}-\text { absorbance }_{\text {sample }}}{\text { absorbance }_{\text {control }}}\right] \times 100 \text {. }
$$

\subsection{Effect of Temperature and $\mathrm{pH}$ on the Particles and the} Antioxidant Capacity. The effect of the temperature was evaluated by placing the particles in an oven at $40^{\circ} \mathrm{C}$ and room temperature $\left(25^{\circ} \mathrm{C}\right)$ for $24 \mathrm{~h}$. The treatment at acidic and basic $\mathrm{pH}$ consisted of mixing $1.0 \mathrm{~mL}$ of the acidic ( $\mathrm{pH} 6$ ) and basic ( $\mathrm{pH} \mathrm{10)}$ solutions, respectively, with the particles $(1.0 \mathrm{mg})$. The samples were vortexed for $1 \mathrm{~min}$. The mixture was placed in an oven at $40^{\circ} \mathrm{C}$ for $24 \mathrm{~h}$. The percentage of the DPPH scavenging activity was determined with the methodology described above.

2.10. Statistical Analysis. Results were expressed as mean\pm standard deviation (SD) and were compared using the analysis of variance (ANOVA) and the Tukey test. Values of $p<0.05$ were indicative of significant differences.

\section{Results and Discussion}

3.1. Encapsulation Efficiency (\%EE). Figure 1 shows the curve of the \%EE of the chia extract in the chitosan particles synthesized by methods A and B by dissolving different concentrations of the extract in the TPP. The extract of chia was obtained with $80 \%$ aqueous ethanol because in previous studies it was determined that in these conditions, the extract has a higher content of phenolic compounds, DPPH radical scavenging activity, and good solubility in water [22].

In the curve, a similar dependence between the $\% \mathrm{EE}$ and the concentration of the chia extract was obtained for both methodologies. The \%EE decreased with the increasing concentration of the extract. Comparable results were reported by Luo et al. [23], Nallamuthu et al. [18], and $\mathrm{Wu}$ et al. [24]. Luo et al. [23] explain that when the concentration 


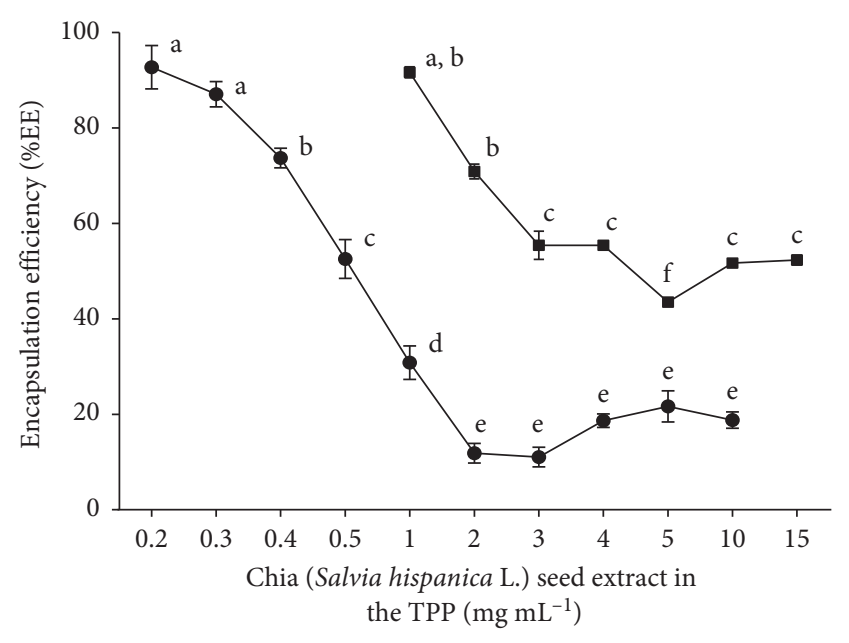

- Method A
- Method B

Figure 1: Encapsulation efficiency (\%EE) curve of the chia (Salvia hispanica L.) seeds extract in chitosan particles synthesized with the methods A and B. Means with different letters are significantly different $(p<0.05)$ according to the Tukey test.

of the active substances increases, it is only electrostatically adsorbed on the surface of the chitosan particles and the extract can separate easily during centrifugation, so the \%EE decreases. The highest \%EE was quantified with a concentration of $0.2 \mathrm{mg} \cdot \mathrm{mL}^{-1}$ with method A. The \%EE begins to decrease with a concentration of $0.4 \mathrm{mg} \cdot \mathrm{mL}^{-1}$ of extract, and with 2.0 to $10.0 \mathrm{mg} \cdot \mathrm{mL}^{-1}$, \%EE is maintained at about $19 \%$. On the other hand, with method B, the highest \%EE was presented with a concentration of $1.0 \mathrm{mg} \cdot \mathrm{mL}^{-1}$ of the extract; therefore, lower concentrations of the extract with this method were not considered. The \%EE began to decrease with a concentration of $2.0 \mathrm{mg} \cdot \mathrm{mL}^{-1}$, and from this, no significant differences were found in the \%EE with the concentrations of extract from 3.0 to $15.0 \mathrm{mg} \cdot \mathrm{mL}^{-1}$. The $\%$ $\mathrm{EE}$ obtained with the extract concentrations of 0.2 to $0.4 \mathrm{mg} \cdot \mathrm{mL}^{-1}(\operatorname{method} \mathrm{A})$ and 1.0 to $2.0 \mathrm{mg} \cdot \mathrm{mL}^{-1}(\operatorname{method} \mathrm{B})$ were higher than that reported in the encapsulation of other compounds such as chlorogenic acid [18] and ferulic acid [25] in chitosan particles. The statistical comparisons between the \%EE values obtained with methods A and B (Figure 1) showed that there are no significant differences between the \%EE of the particles synthesized with 0.2 and 0.3 $(\operatorname{method} \mathrm{A})$ and $1.0 \mathrm{mg} \cdot \mathrm{mL}^{-1}(\operatorname{method} \mathrm{B})$, between the particles with 0.4 (method A) and $2.0 \mathrm{mg} \cdot \mathrm{mL}^{-1}$ (method B), as well as among the particles synthesized with 0.5 (method A) and $3.0,4.0,10.0$, and $15.0 \mathrm{mg} \cdot \mathrm{mL}^{-1}(\operatorname{method} \mathrm{B})$ of the chia extract. However, the main differences found between the particles are the amounts of encapsulated extract. These differences depend directly on the conditions of synthesis. As detailed in the Materials and Methods section, for the evaluated methods $\mathrm{A}$ and $\mathrm{B}, \mathrm{CH}$ with the same molecular weight and degree of deacetylation was used. The mass ratio between the precursors ( $\mathrm{CH}:$ TPP, $3: 1)$ and the temperature of the synthesis were the same, but the concentration of the precursors ( $\mathrm{CH}$ and $\mathrm{TPP})$, the $\mathrm{pH}$ of the $\mathrm{CH}$ solution, and the stirring time were different. Method B uses seven times more amount of $\mathrm{CH}$ and TPP. Method B uses a higher concentration of $\mathrm{CH}$, which increases the viscosity of the solution. It has been reported that an increase in viscosity hinders the mobility of the molecule to be encapsulated around the $\mathrm{CH}$ chain, obtaining low concentrations of the extract in the particles.

The effect of $\mathrm{pH}$ on the encapsulation of the extracts in chitosan particles has not been studied. However, in the encapsulation of some polar molecules, it is mentioned that the increase in the $\mathrm{pH}$ of the $\mathrm{CH}$ solution causes that the molecules gain a negative surface charge. This negative charge favors the electrostatic interaction with the $\mathrm{CH}$ (positive charge); therefore, a higher \%EE is obtained [26]. The $\mathrm{pH}$ of the $\mathrm{CH}$ solution in method $\mathrm{A}(\mathrm{pH} 4.8)$ is higher than the $\mathrm{pH}$ of the solution of method $\mathrm{B}(\mathrm{pH} 2.8)$, which may favor the encapsulation of a greater amount of extract. Regarding the stirring time during the synthesis of the particles, Chopra et al. [27] reported a decrease in the amount of streptomycin encapsulated in chitosan particles by increasing the agitation time of the synthesis. In method $\mathrm{B}$, the magnetic stirring time is longer than in method A. A longer stirring time could cause separation of the extract that is weakly bound to the nanoparticles.

3.2. Nonencapsulated Extract (\%NE), Loading Capacity (\% $L C)$, and Particle Yield (\%PY). The \%NE, \%LC, and \%PY were determined in the particles synthesized with concentrations of the extract of $0.2,2.0$, and $10.0 \mathrm{mg} \cdot \mathrm{mL}^{-1}$ (method A) and 1.0, 4.0, and $15.0 \mathrm{mg} \cdot \mathrm{mL}^{-1}$ (method B) (Table 1). These samples were chosen because they generated significant changes in the \%EE curve and correspond to the low, medium, and high concentrations of the chia extract (Figure 1). \% LC is an important parameter in the particles that encapsulate active substances because it indicates the percentage of extract in the dry particles; thus, the dose of the particles depends on this parameter [18]. In both methodologies, it was observed that as the amount of extract increases, the \%LC also increases. Woranuch and Yoksan [28] obtained similar results in the encapsulation of eugenol in chitosan nanoparticles.

The chia extract is more retained in the chitosan particles made under the conditions of synthesis of method A. The \% LC of the particles synthesized with method B was lower than that with method A. The particles synthesized with $10.0 \mathrm{mg} \cdot \mathrm{mL}^{-1}$ of chia extract with method A presented the highest \%LC. However, the \%EE is low, $18.8 \%$, so during the synthesis of the particles, $81.2 \%$ of the extract added is lost, as shown in \%NE. This represents a disadvantage in its production. On the other hand, for the particles prepared with a concentration of $0.2 \mathrm{mg} \cdot \mathrm{mL}^{-1}$ of extract, the \% LC is $16.2 \%$ and, in these particles, the amount of extract that is wasted is lower. The \%LC of the particles synthesized with method A was higher than that reported in the encapsulation of resveratrol and eugenol in chitosan nanoparticles [24, 28]. In method B, the particles that showed the highest \%EE managed to immobilize only $3.2 \%$ of the extract with a \%NE of $8.3 \%$. The particles elaborated with a concentration of 
TABLE 1: Encapsulation efficiency (\%EE), nonencapsulated extract (\%NE), loading capacity (\%LC), and particle yield (\%PY) of the chitosan particles loaded with the chia (Salvia hispanica L.) seeds extract.

\begin{tabular}{|c|c|c|c|c|c|}
\hline Method & Particles with extract of chia $\left(\mathrm{mg} \cdot \mathrm{mL}^{-1}\right)$ & $\% \mathrm{EE}$ & $\% \mathrm{NE}$ & \%LC & $\% \mathrm{PY}$ \\
\hline \multirow{4}{*}{ A } & 0.0 & $0.0 \pm 0.0^{f}$ & $0.0 \pm 0.0^{\mathrm{g}}$ & $0.0 \pm 0.0^{f}$ & $38.7 \pm 5.4^{\mathrm{d}}$ \\
\hline & 0.2 & $92.7 \pm 4.5^{\mathrm{a}}$ & $7.2 \pm 4.5^{\mathrm{f}}$ & $16.2 \pm 1.5^{\mathrm{c}}$ & $47.2 \pm 4.5^{\mathrm{c}, \mathrm{d}}$ \\
\hline & 2.0 & $11.8 \pm 2.0^{\mathrm{e}}$ & $88.1 \pm 2.0^{\mathrm{a}}$ & $15.1 \pm 1.2^{\mathrm{c}}$ & $51.5 \pm 4.1^{\mathrm{c}}$ \\
\hline & 10.0 & $18.8 \pm 1.7^{\mathrm{d}}$ & $81.1 \pm 1.7^{\mathrm{b}}$ & $72.5 \pm 1.8^{\mathrm{a}}$ & $55.4 \pm 1.9^{\mathrm{c}}$ \\
\hline \multirow{4}{*}{ B } & 0.0 & $0.0 \pm 0.0^{\mathrm{f}}$ & $0.0 \pm 0.0^{\mathrm{g}}$ & $0.0 \pm 0.0^{\mathrm{f}}$ & $71.5 \pm 1.6^{\mathrm{a}}$ \\
\hline & 1.0 & $91.6 \pm 1.1^{\mathrm{a}}$ & $8.3 \pm 1.1^{\mathrm{e}}$ & $3.2 \pm 0.0^{\mathrm{e}}$ & $69.4 \pm 0.5^{\mathrm{a}}$ \\
\hline & 4.0 & $55.4 \pm 0.9^{\mathrm{b}}$ & $44.6 \pm 0.9^{\mathrm{d}}$ & $8.5 \pm 0.2^{\mathrm{d}}$ & $62.0 \pm 1.5^{\mathrm{b}}$ \\
\hline & 15.0 & $52.3 \pm 1.0^{\mathrm{c}}$ & $47.6 \pm 1.0^{c}$ & $26.5 \pm 1.0^{\mathrm{b}}$ & $62.3 \pm 2.4^{\mathrm{b}}$ \\
\hline
\end{tabular}

The results show the means \pm SD. Values with different letters as superscripts in each column are significantly different according to the Tukey test $(p<0.05)$.

$15.0 \mathrm{mg} \cdot \mathrm{mL}^{-1}$ presented a higher $\% \mathrm{LC}$ than the other particles synthesized with the same method, but the loss of extract during the synthesis is $47.6 \%$. As explained previously, the increase in the concentration of $\mathrm{CH}$ and TPP, the $\mathrm{pH}$ of the $\mathrm{CH}$ solution, and the stirring time in method $\mathrm{B}$ could limit the interaction between the extract and the precursors, thus generating a low \%LC. The particles with the highest \%EE elaborated with method A presented a \%PY of $47.2 \%$, and no significant differences were found between the yield of the blank particles and those that encapsulate the chia extract. Different results were obtained with method $B$. The yields of these particles were higher than the yields of the particles made with method A. It was observed that when increasing the concentration of the extract, the yields of the particles decrease lightly in method B. Dudhani and Kosaraju [29] reported that the decrease in particle yields may be caused by the greater competition between the $\mathrm{OH}$ groups of phenolic compounds and the phosphate groups of the TPP for their binding with $\mathrm{CH}$ amino groups, resulting in not many particles forming.

\subsection{Structural Characterization of the Particles by FTIR.}

The FTIR spectra of the extract of chia, blank particles, loaded particles, and the precursors of their synthesis $(\mathrm{CH}$ and TPP) are shown in Figures 2(a) (method A) and 2(b) (method B). Previously, in aqueous alcohol extracts of chia seeds have been identified compounds such as myricetin, quercetin, kaempferol, and phenolic acids [2, 3]. Characteristic bands of this type of compounds were observed in the FTIR spectrum of the chia extract (Figures 2(a), and 2(b) (6)). The broadband in the region of $3300-3000 \mathrm{~cm}^{-1}$ corresponds to the stretching vibrations of the $\mathrm{O}-\mathrm{H}$ bond. Additionally, the signals located at $2922 \mathrm{~cm}^{-1}$ and $2852 \mathrm{~cm}^{-1}$, which are associated with the stretching vibrations of the C-H bonds [30] and the bands in the region of $1600-1400 \mathrm{~cm}^{-1}$, are attributed to the carbonyl and aromatics groups, basic constituents in the structure of phenolic compounds [31].

The signals in the region of $3700-2800 \mathrm{~cm}^{-1}$ in the $\mathrm{CH}$ spectra (Figures 2(a), and 2(b) (1)) correspond to the stretching vibrations of the $\mathrm{O}-\mathrm{H}, \mathrm{N}-\mathrm{H}$, and $\mathrm{C}-\mathrm{H}$ bonds $[9,32]$. The bands located at $1648 \mathrm{~cm}^{-1}$ and $1557 \mathrm{~cm}^{-1}$ arise from the symmetric stretching vibrations of the carbonyl and amino groups, respectively $[9,33]$.
These signals in the spectra of the particles prepared with methods A (Figure 2(a) $(2,3,4,5))$ and B (Figure 2(a) $(2,3,4$, 5)), blank and with extract, shift to $1636 \mathrm{~cm}^{-1}$ and $1542 \mathrm{~cm}^{-1}$, respectively. In addition to that, the signal of the amino group increases in intensity. Furthermore, the signals located at $1024 \mathrm{~cm}^{-1}$ and $891 \mathrm{~cm}^{-1}$ correspond to the stretching vibration of the phosphate group by the incorporation of TPP. It has been described that these changes are due to the interaction between the amino group of chitosan and TPP, proving the formation of the particles $[19,32,34]$. No differences were found between the spectra of the particles without extract and the particles loaded with $0.2 \mathrm{mg} \cdot \mathrm{mL}^{-1}$ of the chia extract synthesized with method A, which suggests that the added extract is encapsulated inside the particle. These results agree with those reported by Zhang et al. [34] in quercetin-loaded chitosan nanoparticles.

In the spectra of the particles synthesized with $2.0 \mathrm{mg} \cdot \mathrm{mL}^{-1}$ and $10.0 \mathrm{mg} \cdot \mathrm{mL}^{-1}$, two absorption bands at $2922 \mathrm{~cm}^{-1}$ and $2852 \mathrm{~cm}^{-1}$ were observed (Figure 2(a) $(4,5)$ ). These bands do not appear in the spectra of the blank particles. The bands correspond to the stretching vibration of the $\mathrm{C}-\mathrm{H}$ bond identified also in the chia extract spectrum. Woranuch and Yoksan [28] explain that the intensity of the signals of the $\mathrm{C}-\mathrm{H}$ bond increases with the concentration of phenolic compounds in the particles. These results suggest that the extract is not only inside the particles but can be adsorbed on the surface of them. Figure 2(a) also shows the schematic representation of the possible location of the chia extract in the particles synthesized with method A.

No differences were found between the spectra of the particles synthesized with $1.0 \mathrm{mg} \cdot \mathrm{mL}^{-1}$ and $4.0 \mathrm{mg} \cdot \mathrm{mL}^{-1}$ and the blank ones elaborated with method B (Figure 2(b) $(3,4)$ ). Therefore, there is a total incorporation of the extract within the structure. However, in the spectrum of the particles synthesized with $15.0 \mathrm{mg} \cdot \mathrm{mL}^{-1}$, weak signals appear at $2922 \mathrm{~cm}^{-1}$ and $2852 \mathrm{~cm}^{-1}$ (Figure 2(b) (5)), which suggests the extract could be inside and adsorbed on the surface of the particles. Figure 2(b) also shows the schematic representation of the possible location of the chia extract in the particles synthesized with method B.

3.4. Particle Size and Morphology. Figure 3 shows the SEM micrographs of the blank and loaded chitosan particles with chia seeds extract. The size of the particles also depends on 


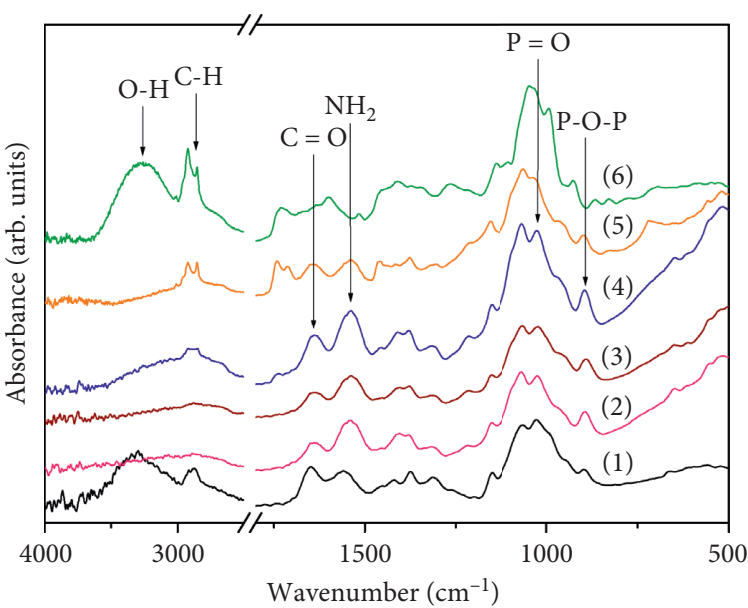

(a)
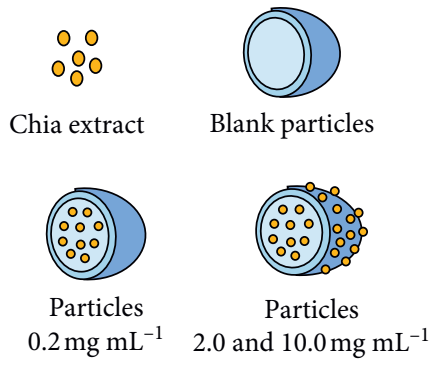

(c)

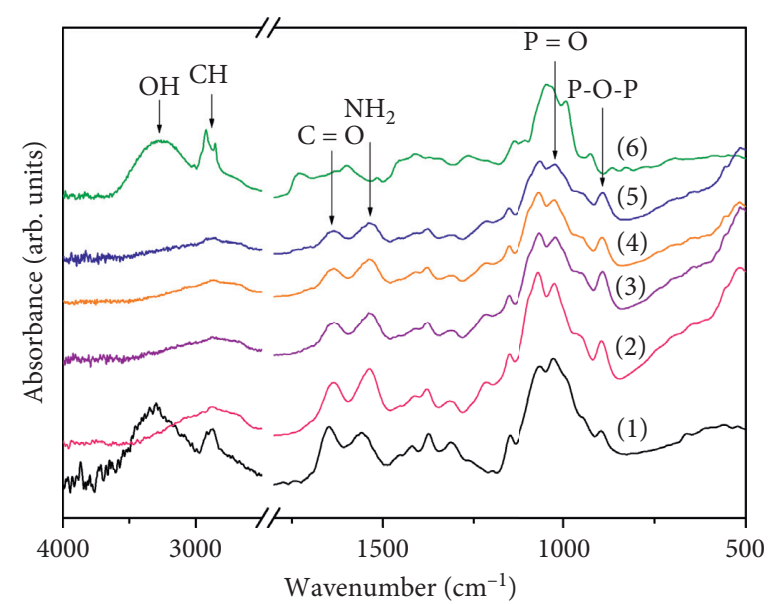

(b)

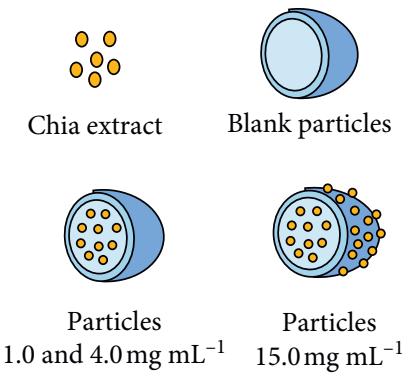

(d)

FIgURE 2: FTIR spectra of chitosan (1), chia extract (6), blank particles (2), and loaded particles with the chia extract synthesized with method A (a): 0.2 (3), 2.0 (4), and $10.0 \mathrm{mg} \cdot \mathrm{mL}^{-1}$ (5). Method B (b): 1.0 (3), 4.0 (4), and $15.0 \mathrm{mg} \cdot \mathrm{mL}^{-1}$ (5). Schematic representation of the structure of the loaded particles synthesized with the methods A (c) and B (d).
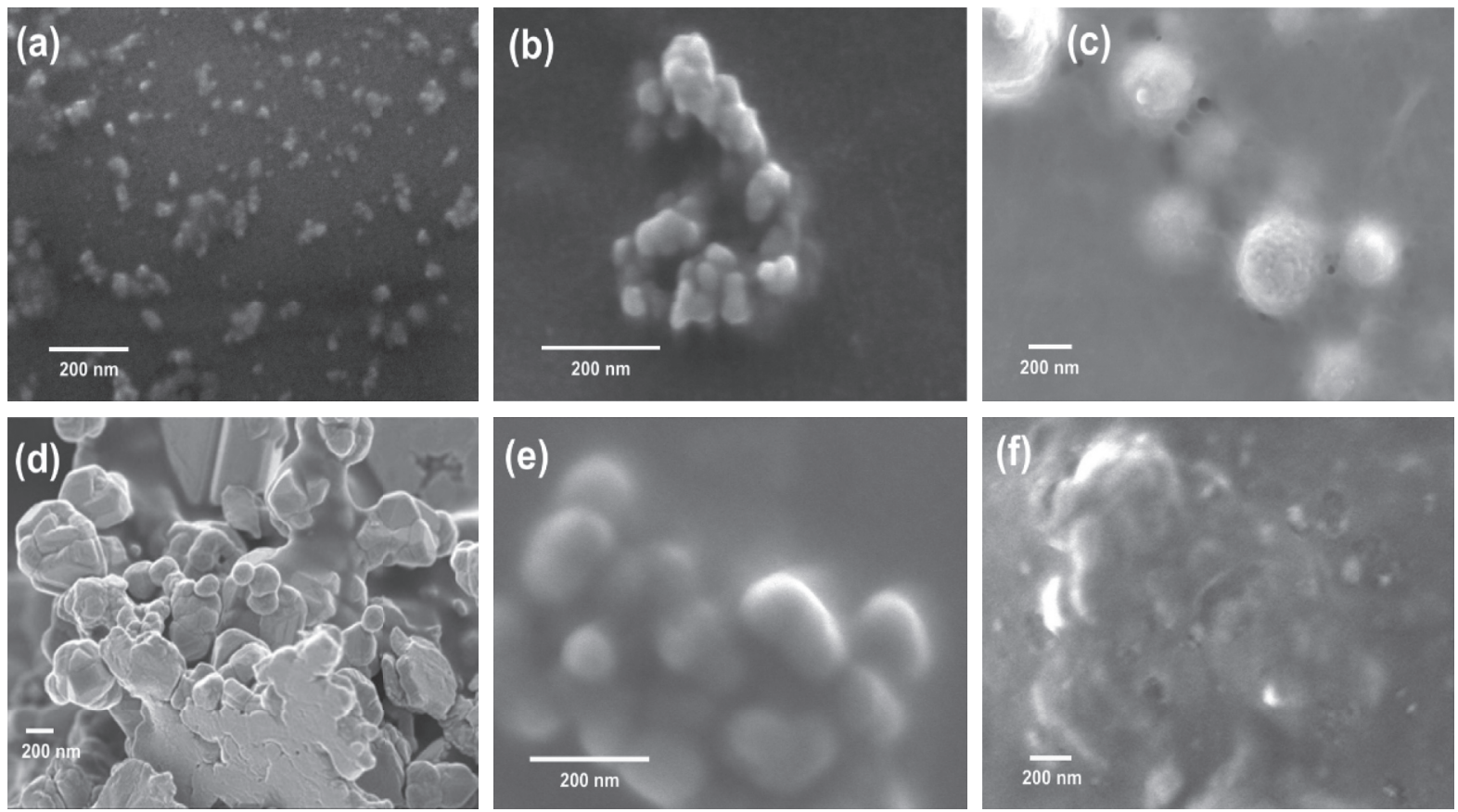

Figure 3: SEM micrographs. Method A: blank particles (a), $0.2 \mathrm{mg} \cdot \mathrm{mL}^{-1}(\mathrm{~b})$, and $10.0 \mathrm{mg} \cdot \mathrm{mL}^{-1}$ (c) chia extract-loaded particles. Method B: blank particles (d), $1.0 \mathrm{mg} \cdot \mathrm{mL}^{-1}(\mathrm{e})$, and $15.0 \mathrm{mg} \cdot \mathrm{mL}^{-1}$ (f) chia extract-loaded particles. 
various factors such as the relationship between the crosslinker (TPP) and the polymer (CH), the molecular weight of the $\mathrm{CH}$, the concentration, the degree of deacetylation, $\mathrm{pH}$, the mechanical energy used during its preparation, and the salinity of the solvents [35].

Method A produces blank particles with an average particle size of $31 \pm 9 \mathrm{~nm}$ (Figure 3(a)). These particles have smaller sizes than those reported by Antoniou et al. [19]. The differences in particle size may be due to the lower molecular weight $(50-100 \mathrm{kDa})$ of the chitosan used by these authors, compared with that used in this investigation $(190-310 \mathrm{kDa})$. In other reports, where the effect of the molecular weight of $\mathrm{CH}$ on particle formation has been evaluated, it has been observed that high molecular weights generate small particles. This phenomenon occurs because, during the magnetic stirring of the chitosan and TPP mixture, the strong flux to which the polymer is subjected can have enough energy to degrade the molecule into small fragments that generate smaller particles $[17,36]$. However, although the formation of individual nanoparticles was observed, also is noticeable the formation of agglomerates between them. The particles synthesized with $0.2 \mathrm{mg} \cdot \mathrm{mL}^{-1}$, whose $\% \mathrm{EE}$ is the highest, showed an average size of $39 \pm 8 \mathrm{~nm}$ (Figure $3(\mathrm{~b})$ ). No significant differences were found between the size of the particles without and with $0.2 \mathrm{mg} \cdot \mathrm{mL}^{-1}$ of chia extract. The spheric morphology of the nanoparticles was observed, but again, as in the previous case showing agglomerates. The particles obtained with a concentration of the extract of $10.0 \mathrm{mg} \cdot \mathrm{mL}^{-1}$ showed an average size of $328 \pm 91 \mathrm{~nm}$ (Figure 3(c)). This increase in particle size is due to the extract loaded in chitosan particles, as reported by other authors $[18,25]$. In this case, is not evident the formation of agglomerates, but large individual particles.

Method B generated blank particles that agglomerate between them during the dry process. An estimation of the average size of these blank particles was complicated, and at the same time, we think this is vague because of their agglomerated nature $(293 \pm 65 \mathrm{~nm})$ (Figure 3(d)). The estimation size of these particles was similar to that reported by Nadirah et al. [20] $(216 \mathrm{~nm})$. These authors used $\mathrm{CH}$ with a molecular weight of $100-300 \mathrm{kDa}$ as a precursor. The particles synthesized with 1.0 and $15.0 \mathrm{mg} \cdot \mathrm{mL}^{-1}$ of the chia extract, according to the SEM micrographs, presented average sizes of $42 \pm 18 \mathrm{~nm}$ (Figure $3(\mathrm{e})$ ) and $76 \pm 24 \mathrm{~nm}$ (Figure 3(f)) respectively, although for this case also it could be vague because the morphology in the image is not very clear. In method A, the increase in the concentration of the extract in the synthesis increased the size of the particles, whereas a contrary behavior was observed in the particles synthesized with method B. The decrease in the size of the particles elaborated with method B may be due to the competition between the phenolic compounds and the phosphate groups of the TPP for their union with the amino groups of $\mathrm{CH}$, as explained above.

The initial $\mathrm{pH}$ of the $\mathrm{CH}$ solution also significantly affects the size of the particles. Antoniou et al. [19] reported that low $\mathrm{pH}$ values in the $\mathrm{CH}$ solution produce strong positively charged amino groups, which lead to repulsion in the $\mathrm{CH}$ chain, resulting in larger particles. The results of these authors are similar to those obtained in this investigation, except for the particles synthesized with $10.0 \mathrm{mg} \cdot \mathrm{mL}^{-1}$ (Method A), the particles made with method B $(\mathrm{CH}$ solution, $\mathrm{pH}$ 2.8) were larger. Stirring time is another factor that has been related to the increase in the particle size because during this procedure the particles can agglomerate [37].

Regarding the morphology of the particles, in some of them, a spherical morphology was observed; in others, the structure is irregular or not very evident. As many authors have reported, chitosan particles tend to form agglomerates, making it difficult to visualize their shape $[9,38]$.

3.5. Dynamic Light Scattering and Zeta Potential. The zeta potential values of the synthesized particles are presented in Table 2. The results show that particles made by method A have potentials between $21.8 \mathrm{mV}$ and $26.3 \mathrm{mV}$. That means the formed colloid is unstable and with a certain tendency to agglomerate [39].

This also is coincident with the size particle distribution results (Figure 4), where wide distributions are observed in the synthesized systems by Method A. The formation of agglomerates is also corroborated in the SEM micrographs.

The results of zeta potential for synthesized particles with method B revealed colloidal systems with better stability $(52.4 \pm 1.9 \mathrm{mV}$ and $39.3 \pm 0.3 \mathrm{mV})$ than those synthesized with method A, except for the particles without chia extract $(26.0 \pm 1.2 \mathrm{mV})$. This was corroborated with the dynamic light scattering results, where the chia extract loaded particles with concentrations of $1.0 \mathrm{mg} \cdot \mathrm{mL}^{-1}$ and $15.0 \mathrm{mg} \cdot \mathrm{mL}^{-1}$ have narrow size distributions.

\subsection{DPPH Radical Scavenging Activity of the Particles}

3.6.1. Effect of Temperature. The DPPH radical scavenging activities of the precursors, blank particles, and chia extractloaded particles were evaluated at $25^{\circ} \mathrm{C}$ and $40^{\circ} \mathrm{C}$, as shown in Figure 5. These temperatures were chosen because one of the possible applications of the particles that encapsulate antioxidants is for food preservation, specifically to delay lipid oxidation and the rancid process. These phenomena can occur at temperatures ranging between $25^{\circ} \mathrm{C}$ and $40^{\circ} \mathrm{C}$ in some places with extreme temperatures. Furthermore, one of the current applications of the particles with extracts is their incorporation into edible films. In many of the edible packaging manufacturing procedures, the solvent is removed at temperatures of $40^{\circ} \mathrm{C}$ or more, so it is important to know the response of the nanoparticles at these temperatures.

Between $25^{\circ} \mathrm{C}$ and $40^{\circ} \mathrm{C}$, the TPP showed no activity. However, $\mathrm{CH}$ at $25^{\circ} \mathrm{C}$ presented a DPPH scavenging activity of $3.7 \%$ and at $40^{\circ} \mathrm{C}$ the activity was lower $(2.4 \%)$. Several authors have described the low antioxidant capacity of $\mathrm{CH}$ $[40,41]$. The antioxidant activity of $\mathrm{CH}$ is due to the protonated amino groups of $\mathrm{C} 2$ that react with the antioxidant agent [40]. The particles prepared without extract (blank, $0.0 \mathrm{mg} \cdot \mathrm{mL}^{-1}$ ) in both methods showed no activity at $25^{\circ} \mathrm{C}$. The amino group of $\mathrm{CH}$ reacts with TPP to form the particle, so linked to the crosslinking agent does not have antioxidant 
TABLE 2: Zeta potential values of synthesized particles by methods A and B and chia extract-loaded particles.

\begin{tabular}{lccc}
\hline \multicolumn{1}{c}{$\begin{array}{c}\text { Method A } \\
\text { Particles with extract of chia }\left(\mathrm{mg} \cdot \mathrm{mL}^{-1}\right)\end{array}$} & Zeta potential $(\mathrm{mV})$ & $\begin{array}{c}\text { Method B } \\
\text { Particles with extract of chia }\left(\mathrm{mg} \cdot \mathrm{mL}^{-1}\right)\end{array}$ & Zeta potential $(\mathrm{mV})$ \\
\hline 0.0 & $21.8 \pm 0.8$ & 0.0 & $26.0 \pm 1.2$ \\
0.2 & $26.3 \pm 0.3$ & 1.0 & $52.4 \pm 1.9$ \\
10.0 & $24.4 \pm 0.3$ & 15.0 & $39.3 \pm 0.3$ \\
\hline
\end{tabular}

The results show the means \pm SD.

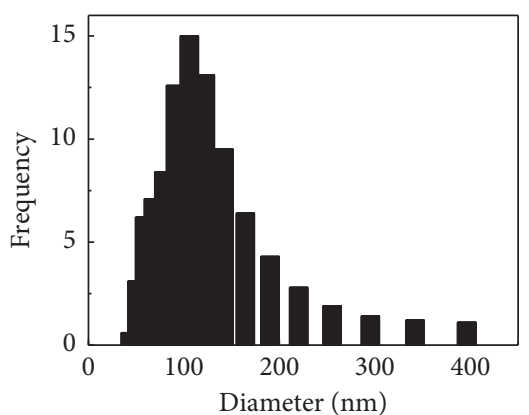

(a)

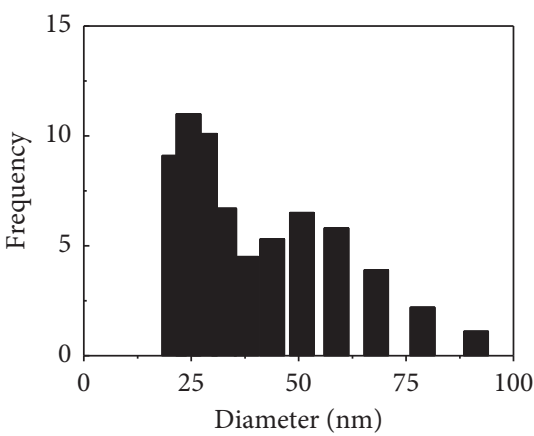

(d)

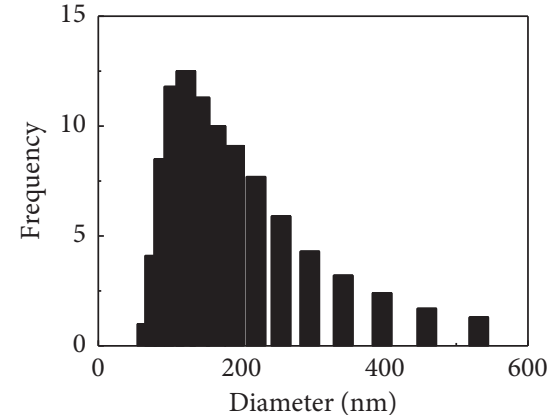

(b)

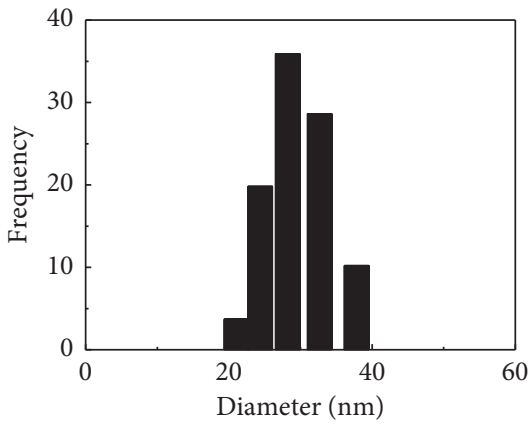

(e)

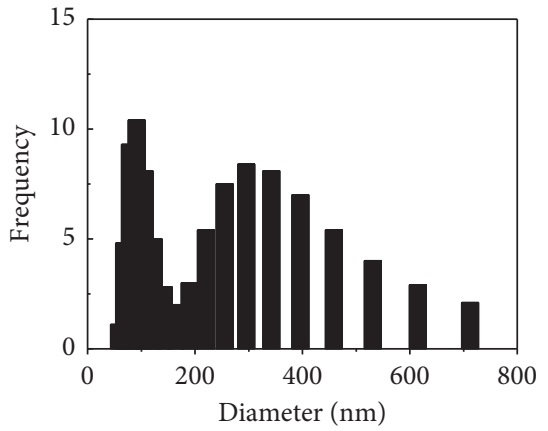

(c)

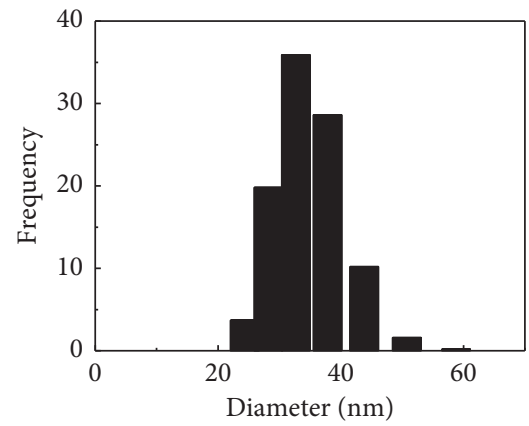

(f)

Figure 4: Particle size distributions. Method A: blank particles (a), $0.2 \mathrm{mg} \cdot \mathrm{mL}^{-1}$ (b), and $10.0 \mathrm{mg} \cdot \mathrm{mL}^{-1}$ (c) chia extract-loaded particles. Method B: blank particles (d), $1.0 \mathrm{mg} \cdot \mathrm{mL}^{-1}(\mathrm{e})$, and $15.0 \mathrm{mg} \cdot \mathrm{mL}^{-1}(\mathrm{f})$ chia extract-loaded particles.

activity. These results agree with those reported by Zhang et al. [34]. The particles synthesized with a concentration of $0.2 \mathrm{mg} \cdot \mathrm{mL}^{-1}(\operatorname{method~A})$ and $1.0 \mathrm{mg} \cdot \mathrm{mL}^{-1}$ and $4.0 \mathrm{mg} \cdot \mathrm{mL}^{-1}$ (method B) showed no DPPH scavenging activity at $25^{\circ} \mathrm{C}$. The lack of antioxidant capacity of these particles loaded with the chia extract suggests that the phenolic compounds are inside as evidenced by the FTIR spectra (Figure 2). Inside of the particles, the compounds do not interact with the DPPH molecule. In contrast, the particles synthesized with 2.0 and $10.0(\operatorname{method} \mathrm{A})$ and $15.0 \mathrm{mg} \cdot \mathrm{mL}^{-1}(\operatorname{method} \mathrm{B})$ of the extract exhibited DPPH scavenging activity at $25^{\circ} \mathrm{C}$. The activity of these particles was significantly higher than the blank particles and $\mathrm{CH}$. This agrees with the FTIR spectra of the particles with such concentrations, where spectral features related to the extract were observed, indicating the adsorption of the extract on the surface of the particles (Figure 2). Therefore, the molecules of the periphery can react with the radical, inhibiting it. The highest DPPH radical scavenging activity at $25^{\circ} \mathrm{C}$ was obtained in the particles synthesized with $10.0 \mathrm{mg} \cdot \mathrm{mL}^{-1}$, which also showed a higher \%LC. That is, these particles contain a higher percentage of extract. The antioxidant capacity of these particles is higher than that reported by $\mathrm{Wu}$ et al. [24] in nanoparticles that incorporate resveratrol.

The particles synthesized with methods A and B showed a greater antioxidant capacity at $40^{\circ} \mathrm{C}$ than at $25^{\circ} \mathrm{C}$. These results suggest that the thermal process at $40^{\circ} \mathrm{C}$ causes the particle to break (Figure 5(b)). The rupture of the particles without extract leaves free chitosan amino groups that can now interact with the DPPH radical and in the particles loaded with the chia extract causes the release of the extract that can react with the radical. Szymańska and Winnicka [42] mention that one of the environmental factors that affect the stability of chitosan is the temperature. Viljoen et al. [43], in the study on the effect of moisture content, temperature, and time of exposure on the physical stability of $\mathrm{CH}$, found that exposure to $40^{\circ} \mathrm{C}$ caused a significant loss of moisture, which resulted in a decrease in the hardness and mechanical strength of the particle made with this polymer. Different results were found in the particles synthesized with 


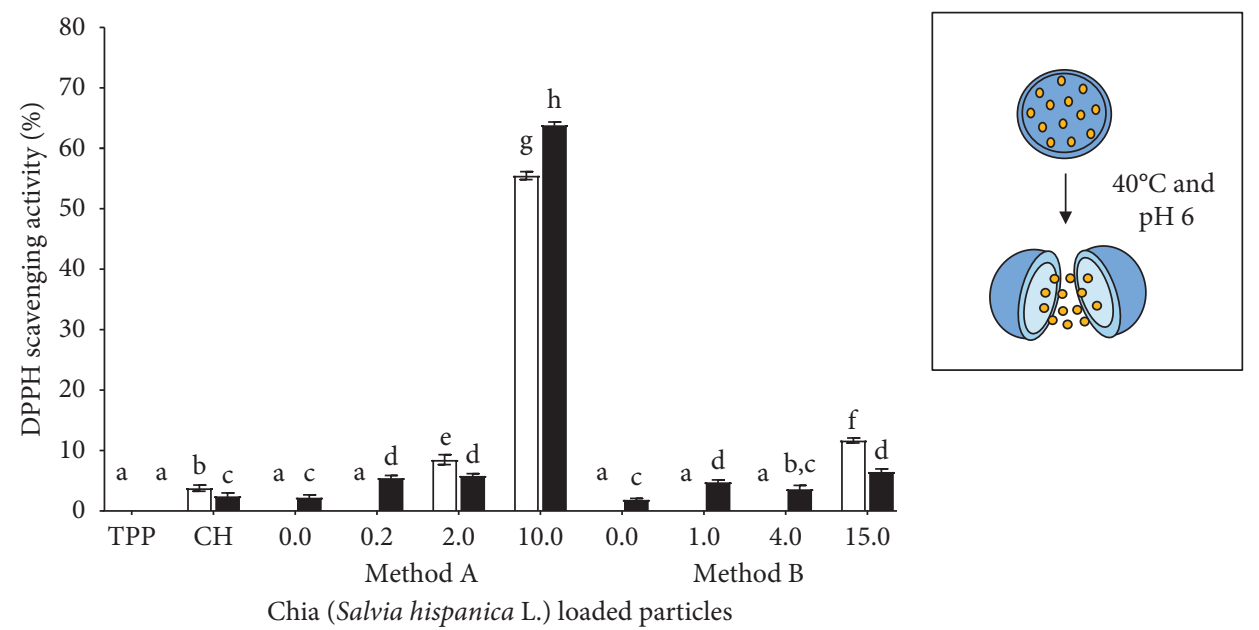

$\square \quad 25^{\circ} \mathrm{C}$
$\square 40^{\circ} \mathrm{C}$

(a)

(b)

FIGURE 5: (a) DPPH radical scavenging activity of precursors (CH and TPP), blank particles $\left(0.0 \mathrm{mg} \cdot \mathrm{mL}^{-1}\right)$, and chia extract-loaded particles with different concentrations synthesized with the methods $\mathrm{A}$ and $\mathrm{B}$ after treatment at $25^{\circ} \mathrm{C}$ and $40^{\circ} \mathrm{C}$. The columns with different letters are significantly different according to the Tukey test $(p<0.05)$. (b) Schematic representation of the effect of the temperature and $\mathrm{pH}$ on the particles.

2.0 and $15.0 \mathrm{mg} \cdot \mathrm{mL}^{-1}$ since a decrease in the antioxidant capacity was observed after treatment at $40^{\circ} \mathrm{C}$. The highest $\mathrm{DPPH}$ scavenging activity at $40^{\circ} \mathrm{C}$ was obtained in the particles synthesized with $10.0 \mathrm{mg} \cdot \mathrm{mL}^{-1}$ of the extract with method A. Except for the particles synthesized with $10.0 \mathrm{mg} \cdot \mathrm{mL}^{-1}$, the DPPH scavenging activity of the particles was less than $10 \%$, and this is because the content of the extract encapsulated in them is small, as demonstrated by the parameter \%LC. In the particles synthesized with 0.2 and $2.0 \mathrm{mg} \cdot \mathrm{mL}^{-1}$ (method A), approximately $15 \%$ is extract, and in those made with 1.0 and $4.0 \mathrm{mg} \cdot \mathrm{mL}^{-1}(\operatorname{method} \mathrm{B})$, only $3 \%$ and $8 \%$ are extract. In contrast, the particles made with $10 \mathrm{mg} \cdot \mathrm{mL}^{-1}$ contain 5 times more of chia extract (\%LC $72.5 \%$ ) and part of this extract may be adsorbed on the surface. The results show that the release of the chia extract from the chitosan particles is favored at $40^{\circ} \mathrm{C}$. Derived from these results, the processes of making edible films by using the casting method can affect the stability of the particles, allowing the extract to be released. The breakdown of these particles could also alter other important properties of films such as their mechanical and barrier properties. This will depend on the characteristics of the polymers used and their interaction with the nanoparticles.

3.6.2. Effect of $p H$. Figure 6 shows the DPPH scavenging activity of the precursors and particles with and without extract after treatment with acidic and basic solutions. The particles were subjected to $\mathrm{pH} 6$ because most of the natural and industrialized foods have this acidic $\mathrm{pH}$ [44]. As mentioned above, one of the possible applications of the particles is their incorporation into food to prevent oxidation. It was also decided to evaluate $\mathrm{pH} 10$ taking into account another application of the particles, their incorporation in filmogenic solutions for obtaining edible films. In this process, the $\mathrm{pH}$ is adjusted to 10 to dissolve the proteins, and under these conditions, the particles are added.

The precursor TPP in acidic and basic conditions did not present DPPH scavenging activity. The antioxidant capacity of $\mathrm{CH}$ was lower than that found at $25^{\circ} \mathrm{C}$ and $40^{\circ} \mathrm{C}$. No significant differences were found between the antioxidant activity of $\mathrm{CH}$ at $\mathrm{pH} 6$ and 10. The highest DPPH scavenging activity at $\mathrm{pH} 6$ and 10 was obtained in the particles synthesized with $10.0 \mathrm{mg} \cdot \mathrm{mL}^{-1}$ extract. Under acidic conditions, the particles made with 2.0 and $10.0 \mathrm{mg} \cdot \mathrm{mL}^{-1}(\operatorname{method~A)}$ and those synthesized with $1.0,4.0$, and $15.0 \mathrm{mg} \cdot \mathrm{mL}^{-1}$ (method B) of the extract presented a higher antioxidant activity than the blank particles. Thus, the release of the chia extract can occur in acidic conditions. It has been described that at low $\mathrm{pH}(<\mathrm{pH} 6.3)$, the amines of chitosan are protonated [45] and the $\mathrm{CH}$ of the particles can be solubilized when treated with acidic solutions so that the particle can be destroyed leaving the extract free. Under basic conditions, only significant differences were found between the antioxidant capacity of the particles synthesized with 10.0 (method A) and $15.0 \mathrm{mg} \cdot \mathrm{mL}^{-1}(\operatorname{method} \mathrm{B})$ of extract and the blank particles. It has been reported that at high $\mathrm{pH}(>\mathrm{pH} 7)$, $\mathrm{CH}$ is insoluble ( $\mathrm{pKa} 6.5$ ) and the amines of this polymer are deprotonated and act as nucleophilic, so the pair of nonshared electrons can react with other molecules present in the medium [45]. This may be the cause of the low antioxidant capacity of the particles treated in a basic medium, mainly in the particles synthesized with method B. These particles present a greater content of $\mathrm{CH}$ and lower \%LC. The results suggest that the particles synthesized with method A could be used for the preservation of acidic or basic foods since the extract can be released under these conditions. Particles made with method B can be used in 


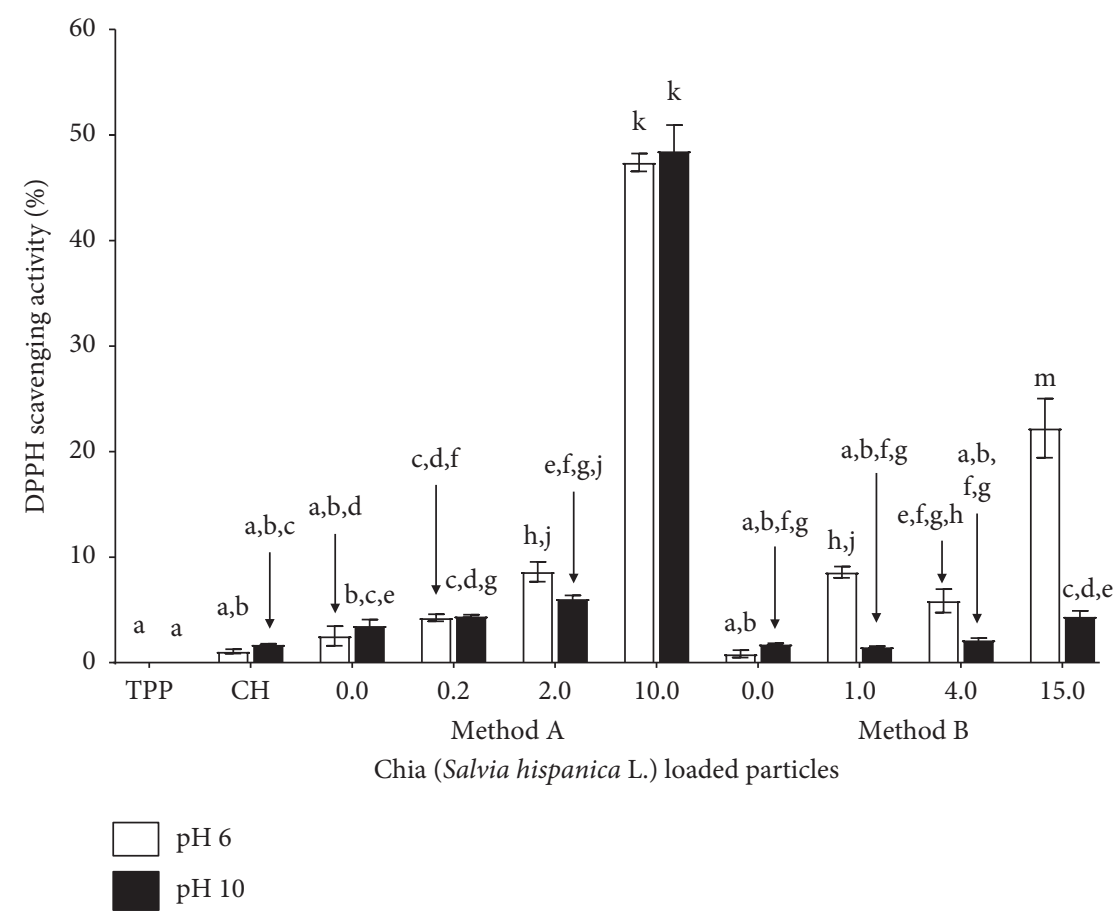

FIGURE 6: DPPH radical scavenging activity of precursors ( $\mathrm{CH}$ and TPP), blank particles $\left(0.0 \mathrm{mg} \cdot \mathrm{mL}^{-1}\right)$, and chia extract-loaded particles with different concentrations synthesized by methods A and B after treatment with acidic and basic solutions. The columns with different letters are significantly different according to the Tukey test $(p<0.05)$.

acidic environments. On the other hand, in filmogenic solutions for food packaging, the particles could remain embedded in their surface without releasing the extract. This extract could later be released under certain environmental conditions or by contact with food.

\section{Conclusions}

The results obtained in the \%EE, \%NE, and \%LC showed that method A is efficient for encapsulating the extract of chia seeds, although as shown by the zeta potential, the particles have a certain tendency to agglomerate. On the other hand, method $\mathrm{B}$ is less efficient than method $\mathrm{A}$; however, the stability of the particles is better, and it could represent a better alternative to enlarge the lifetime of the encapsulated extract. The structural analysis performed with FTIR proved the formation of the particles and suggested the location of the extract in the particles, totally encapsulated or adsorbed on the surface. The evaluated methods allowed the obtaining of particles with a high\% EE presented average sizes between $\sim 31$ and $328 \mathrm{~nm}$. The particles in which the extract was adsorbed on the surface showed antioxidant activity at $25^{\circ} \mathrm{C}$. However, in the particles that only encapsulate the extract, it was observed that the acidic conditions and a temperature of $40^{\circ} \mathrm{C}$ allowed the release of the extract, so they presented a greater antioxidant activity. The results obtained in this work can be useful to synthesize antioxidant chia extract-loaded chitosan particles with specific characteristics according to their future applications and can serve as a basis for the encapsulation of other antioxidant extracts isolated from plant species. The particles are loaded with chia extract, which could be used as antioxidants in functional and nutraceuticals foods, in the cosmetics and pharmaceutical industries, and even in edible films for food packaging.

\section{Data Availability}

The data used to support the findings of this study are included within the article.

\section{Conflicts of Interest}

All authors declare no conflicts of interest.

\section{Acknowledgments}

The authors thank the Comision de Operacion y Fomento de Actividades Academicas del IPN and Secretaría de Investigación y Posgrado-IPN for financial support and Consejo Nacional de Ciencia y Tecnología (CONACyT) for the scholarship (236173) to G. Morales-Olán to obtain her PhD degree. Additionally, the authors would like to acknowledge Centro de Nanociencias y Micro y Nanotecnologías (CNMN) and Dr. Hugo Martinez Gutiérrez from Instituto Politécnico Nacional for SEM assays.

\section{References}

[1] V. Y. Ixtaina, S. M. Nolasco, and M. C. Tomás, "Physical properties of chia (Salvia hispanica L.) seeds," Industrial Crops and Products, vol. 28, no. 3, pp. 286-293, 2008.

[2] E. Reyes-Caudillo, A. Tecante, and M. A. Valdivia-López, "Dietary fibre content and antioxidant activity of phenolic 
compounds present in Mexican chia (Salvia hispanica L.) seeds," Food Chemistry, vol. 107, no. 2, pp. 656-663, 2008.

[3] O. Martínez-Cruz and O. Paredes-López, "Phytochemical profile and nutraceutical potential of chia seeds (Salvia hispanica L.) by ultra high performance liquid chromatography," Journal of Chromatography A, vol. 1346, pp. 43-48, 2014.

[4] M. J. Rahman, A. C. De Camargo, and F. Shahidi, "Phenolic and polyphenolic profiles of chia seeds and their in vitro biological activities," Journal of Functional Foods, vol. 35, pp. 622-634, 2017.

[5] E. Corona-Jiménez, N. Martínez-Navarrete, H. Ruiz-Espinosa, and J. Carranza-Concha, "Ultrasound-assisted extraction of phenolics compounds from chia (Salvia hispanica L.) seeds and their antioxidant activity," Agrociencia, vol. 50, pp. 403-412, 2016.

[6] Z. Jia, M.-J. Dumont, and V. Orsat, "Encapsulation of phenolic compounds present in plants using protein matrices," Food Bioscience, vol. 15, pp. 87-104, 2016.

[7] L. N. Bell, R. E. C. Wildman, Stability testing of nutraceuticals and functional foods," in Handbook of Nutraceuticals and Functional FoodsCRC Press, New York, NY, USA, 2001.

[8] M. Vincekovic, M. Viskic, S. Juric et al., "Innovative technologies for encapsulation of mediterranean plants extracts," Trends in Food Science and Technology, vol. 69, pp. 1-12, 2017.

[9] A. Esmaeili and A. Asgari, "In vitro release and biological activities of Carum copticum essential oil (CEO) loaded chitosan nanoparticles," International Journal of Biological Macromolecules, vol. 81, pp. 283-290, 2015.

[10] G. C. Feyzioglu and F. Tornuk, "Development of chitosan nanoparticles loaded with summer savory (Satureja hortensis L.) essential oil for antimicrobial and antioxidant delivery applications," LWT, vol. 70, pp. 104-110, 2016.

[11] L. M. Julio, C. N. Copado, B. W. K. Diehl, V. Y. Ixtaina, and M. C. Tomás, "Chia bilayer emulsions with modified sunflower lecithins and chitosan as delivery systems of omega-3 fatty acids," $L W T$, vol. 89, pp. 581-590, 2018.

[12] A. González, M. L. Martínez, A. J. Paredes, A. E. León, and P. D. Ribotta, "Study of the preparation process and variation of wall components in chia (Salvia hispanica L.) oil microencapsulation," Powder Technology, vol. 301, pp. 868-875, 2016.

[13] B. Firtin, H. Yenipazar, A. Saygün, and N. Şahin-Yeşilçubuk, "Encapsulation of chia seed oil with curcumin and investigation of release behavior \& antioxidant properties of microcapsules during in vitro digestion studies," LWT-Food Science and Technology, vol. 134, p. 109947, 2020.

[14] U. Us-Medina, J. Ruiz-Ruiz, P. Quintana-Owen, and M. Segura-Campos, "Salvia hispanica mucilage-alginate properties and performance as an encapsulation matrix for chia seed oil," Journal of Food Processing and Preservation, vol. 41, no. 6, p. e13270, 2017.

[15] C. De Campo, P. P. Dos Santos, T. M. H. Costa et al., "Nanoencapsulation of chia seed oil with chia mucilage (Salvia hispanica L.) as wall material: characterization and stability evaluation," Food Chemistry, vol. 234, pp. 1-9, 2017.

[16] Y. Yang, Z. Zhang, S. Li, X. Ye, X. Li, and K. He, "Synergy effects of herb extracts: pharmacokinetics and pharmacodynamic basis," Fitoterapia, vol. 92, pp. 133-147, 2014.

[17] B. Hu, C. Pan, Y. Sun et al., "Optimization of fabrication parameters to produce Chitosan-Tripolyphosphate nanoparticles for delivery of tea catechins," Journal of Agricultural and Food Chemistry, vol. 56, no. 16, pp. 7451-7458, 2008.

[18] I. Nallamuthu, A. Devi, and F. Khanum, "Chlorogenic acid loaded chitosan nanoparticles with sustained release property, retained antioxidant activity and enhanced bioavailability," Asian Journal of Pharmaceutical Sciences, vol. 10, no. 3, pp. 203-211, 2015.

[19] J. Antoniou, F. Liu, H. Majeed, J. Qi, W. Yokoyama, and F. Zhong, "Physicochemical and morphological properties of size-controlled chitosan-tripolyphosphate nanoparticles," Colloids and Surfaces A: Physicochemical and Engineering Aspects, vol. 465, pp. 137-146, 2015.

[20] A. Nadirah, S. Fun, S. Cem, and L. Maurice, "Preparation and characterization of chitosan nanoparticles-doped cellulose films with antimicrobial property," Journal of Nanomaterials, vol. 201410 pages, 2014.

[21] I. Parejo, F. Viladomat, J. Bastida et al., "Comparison between the radical scavenging activity and antioxidant activity of six distilled and nondistilled mediterranean herbs and aromatic plants," Journal of Agricultural and Food Chemistry, vol. 50, no. 23, pp. 6882-6890, 2002.

[22] G. Morales-Olán, M. Rojas-López, J. Díaz-Reyes, F. F. RosasCárdenas, and S. Luna-Suárez, "Effect of ethanol and methanol on the total phenolic content and antioxidant capacity of chia seeds (Salvia hispanica L.)," Sains Malaysiana, vol. 49, no. 6, pp. 1283-1292, 2020.

[23] Y. Luo, B. Zhang, W.-H. Cheng, and Q. Wang, "Preparation, characterization and evaluation of selenite-loaded chitosan/ TPP nanoparticles with or without zein coating," Carbohydrate Polymers, vol. 82, no. 3, pp. 942-951, 2010.

[24] J. Wu, Y. Wang, H. Yang, X. Liu, and Z. Lu, "Preparation and biological activity studies of resveratrol loaded ionically crosslinked chitosan-TPP nanoparticles," Carbohydrate Polymers, vol. 175, pp. 170-177, 2017.

[25] R. Panwar, S. C. Pemmaraju, A. K. Sharma, and V. Pruthi, "Efficacy of ferulic acid encapsulated chitosan nanoparticles against Candida albicans biofilm," Microbial Pathogenesis, vol. 95, pp. 21-31, 2016.

[26] C. Mattu, C. R. Li, and G. Ciardelli, "Chitosan nanoparticles as therapeutic protein nanocarriers: the effect of $\mathrm{pH}$ on particle formation and encapsulation efficiency," Polymer Composites, vol. 34, no. 9, pp. 1538-1545, 2013.

[27] M. Chopra, P. Kaur, M. Bernela, and R. Thakur, "Synthesis and optimization of streptomycin loaded chitosan-alginate nanoparticles," International Journal of Scientific and Technology Research, vol. 1, no. 10, pp. 31-34, 2012.

[28] S. Woranuch and R. Yoksan, "Eugenol-loaded chitosan nanoparticles: I. thermal stability improvement of eugenol through encapsulation," Carbohydrate Polymers, vol. 96, pp. 578-585, 2013.

[29] A. Dudhani and S. Kosaraju, "Bioadhesive chitosan nanoparticles: preparation and characterization," Carbohydrate Polymers, vol. 81, pp. 243-251, 2010.

[30] M. Cobaleda, N. Almaraz, R. E. Alanis et al., "Rapid determination of phenolics, flavonoids, and antioxidant properties of Physalis ixocarpa Brot ex Hornem and Physalis angulata L. by infrared spectroscopy and partial least squares," Analytical Letters, vol. 51, pp. 523-536, 2017.

[31] S. D. Silva, R. P. Feliciano, L. V. Boas, and M. R. Bronze, "Application of FTIR-ATR to Moscatel dessert wines for prediction of total phenolic and flavonoid contents and antioxidant capacity," Food Chemistry, vol. 150, no. 1, pp. 489-493, 2014.

[32] A. Rampino, M. Borgogna, P. Blasi, B. Bellich, and A. Cesaro, "Chitosan nanoparticles: preparation, size evolution and stability," International Journal of Pharmaceutics, vol. 455, pp. 219-228, 2013. 
[33] G. Furtado, T. Bizerra, R. Alves, J. De Lima, M. Rodríguez, and M. Lia, "Chitosan/NaF particles prepared via ionotropic gelation: evaluation of particles size and morphology," Materials Research, vol. 21, no. 4, pp. 1-8, 2018.

[34] Y. Zhang, Y. Yang, K. Tang, X. Hu, and G. Zou, "Physicochemical characterization and antioxidant activity of quercetin-loaded chitosan nanoparticles," Journal of Applied Polymer Science, vol. 107, pp. 891-897, 2008.

[35] H. Jonassen, A. Kjoniksen, and M. Hiorth, "Effects of ionic strength on the size and compactness of chitosan nanoparticles," Colloid and Polymer Science, vol. 290, pp. 919-929, 2012.

[36] M. Tsai, S. Bai, and R. Chen, "Cavitation effects versus stretch effects resulted in different size and polydispersity of ionotropic gelation chitosan-sodium tripolyphosphate nanoparticle," Carbohydrate Polymers, vol. 71, pp. 448-457, 2008.

[37] Y. Villegas-Peralta, Y. M. A. Correa-Murrieta, E. MezaEscalante, E. Flores-Aquino, J. Álvarez-Sanchez, and R. G. Sanchez-Duarte, "Effect of the preparation method in the size of chitosan nanoparticles for the removal of allura red dye," Polymer Bulletin, vol. 76, pp. 4415-4430, 2019.

[38] H. Zhang, S. Wu, Y. Tao, L. Zang, and Z. Su, "Preparation and characterization of water-soluble chitosan nanoparticles as protein delivery system," Journal of Nanomaterials, vol. 2010, 5 pages, 2010.

[39] T. Ivancica, M. R. Thompsona, J. L. Pawlakb, and D. J. W Lawtonc, "Influence of anionic and non-ionic surfactants on nanoparticle synthesis by solvent-free extrusion emulsification," Colloids and Surfaces A: physicochemical and Engineering Aspects, vol. 587, p. 124328, 2020.

[40] T. Trung and H. Nguyen, "Physicochemical properties and antioxidant activity of chitin and chitosan prepared from pacific white shrimp waste," International Journal of Carbohydrate Chemistry, vol. 20156 pages, 2015.

[41] Q. Li, L. Wei, J. Zhang, G. Gu, and Z. Guo, "Significantly enhanced antioxidant activity of chitosan through chemical modification with coumarins," Polymer Chemistry, vol. 10, pp. 1480-1488, 2019.

[42] E. Szymańska and K. Winnicka, "Stability of Chitosan-A challenge for pharmaceutical and biomedical applications," Marine Drugs, vol. 13, pp. 1819-1846, 2015.

[43] J. M. Viljoen, J. H. Steenekamp, A. F. Marais, and A. F. Kotzé, "Effect of moisture content, temperature and exposure time on the physical stability of chitosan powder and tablets," Drug Development and Industrial Pharmacy, vol. 40, no. 6, pp. 730-742, 2014.

[44] P. Casaubon-Garcín, P. Lamshing-Salinas, F. Isoard-Acosta, S. Casaubon, D. Delgado-Franco, and A. Pérez-Lizaur, "pH de los alimentos: una herramienta para el manejo de los pacientes con reflujo gastroesofágico," Revista Mexicana de Pediatría, vol. 85, no. 3, pp. 89-94, 2018.

[45] G. Kumar, P. J. Smith, and G. F. Payne, "Enzymatic grafting of a natural product onto chitosan to confer water solubility under basic conditions," Biotechnology and Bioengineering, vol. 63, no. 2, pp. 154-165, 1999. 